\title{
Coalition of advocates to vaccinate of Western European citizens aged 60 years and older
}

\author{
Jean-Pierre Michel1 ${ }^{1}$ Christian Chidiac'2, Beatrix Grubeck-Loebenstein ${ }^{3}$, Robert W. Johnson ${ }^{4}$, \\ Paul Henri Lambert ${ }^{5}$, Stefania Maggi ${ }^{6}$, Robert Moulias ${ }^{7}$, Karl Nicholson ${ }^{8}$ and Hans Werner ${ }^{9}$ \\ 1Department of Rehabilitation and Geriatrics, Geneva Medical School and University Hospitals, \\ Thonex-Geneve, Switzerland, 2Service des Maladies Infectieuses et Tropicales, Hôpital de la Croix-Rousse, \\ Inserm U851, Lyon, France, 3 Institute for Biomedical Aging Research, Innsbruck, Austria, ${ }^{3}$ Bristol Royal \\ Infirmary and University of Bristol, Bristol, United Kingdom, 5CMU, Centre of Vaccinology, Geneva, \\ Switzerland, ${ }^{6} \mathrm{CNR}$, Center on Aging, Padova, Italy, ${ }^{2}$ Service de Médecine Interne, Hôpital Charles-Foix, \\ Ivry-sur-Seine, France, 8University Hospitals of Leicester NHS Trust, Leicester Royal Infirmary, Leicester, \\ United Kingdom, ${ }^{9}$ Ev. Krankenhaus Elisabethenstift, Darmstadt, Germany
}

ABSTRACT. The high burden of infectious diseases in adults aged 60 years and older is disproportionate, considering that many of these diseases are vaccine-preventable. Based on careful analysis of the reasons for vaccination barriers/failures in the European population, the two European geriatric and gerontological societies (the European Union Geriatric Medicine Society [EUGMS] and the International Association of Gerontology and Geriatrics - European Region [IAGG-ER]) propose careful adaptation of current vaccine guidelines to promote preventive aspects, concerning both life threatening-diseases (influenza, pneumococcal pneumonia and tetanus/diphtheria) and diseases which adversely impact patients' quality of life (pertussis and herpes zoster). This consensus statement is designed to support official recommendations and improve the willingness to vaccinate the most rapidly growing segment of the population. The following guidelines are based on the importance of the sustainability of vaccine programs from midlife till extreme old age:

- Promote healthy aging by optimizing health determinants of daily functions, active participation in society and individual quality of life;

- Provide useful information to contribute toward harmonizing vaccine strategies at European level;

- Support the public health, social and economic values of vaccination.

Both healthcare professionals and consumers associations have a critical role to play in the implementation of such consensus clinical guidelines.

(Aging Clin Exp Res 2009; 21: 254-257)

○2009, Editrice Kurtis
The European geriatric and gerontological societies [European Union Geriatric Medicine Society (EUGMS) and International Association of Gerontology and Geriatrics - European Region (IAGG-ER)], concerned with the public health burden of vaccine-preventable diseases, convened a Working Group of experts, chaired by the academic director of the EUGMS (JPM) for the purpose of advocating higher immunization rates among European citizens aged 60 years and older.

The main purposes of the Joint Working Group were: 1 ) to conduct an inventory of the current practical guidelines for universally recommended vaccines in adults in $\mathrm{Eu}-$ ropean countries, and to compare guidelines with those of the USA; 2) to propose an adaptation of current vaccine guidelines designed to support official recommendations; 3 ) to stress the importance of sustaining a lifecourse vaccine program from childhood to adulthood until extreme old age; 4) to support the public health, social and economic value of vaccines to prevent infectious diseases in the whole population; and 5) to enhance the willingness to vaccinate and the public acceptance of vaccination.

The group was composed of geriatricians designated by the two societies (EUGMS: SM and JPM and IAGG-ER: $\mathrm{RM}$ and $\mathrm{HW}$ ) and experts in immunology and vaccines (BGL and PHL), pneumococcal vaccine (CC) and influenza vaccine $(\mathrm{KN})$ and public health (Theri Kilpi), who all worked on a voluntary basis.

Each of the working member was in charge of a specific topic (formulating the bibliography, reporting at each of the three meetings, and participating in the writ-

Key words: Healthy aging, public health, vaccine.

Correspondence: Jean-Pierre Michel, MD, Department of Rehabilitation and Geriatrics, Geneva Medical School and University Hospitals, Chemin Pont Bochet, 3 Thonex-Geneve, $\mathrm{CH}$ 1226, Switzerland.

E-mail: Jean-Pierre.Michel@hcuge.ch

Received March 9, 2009; accepted in revised form April 26, 2009. 
ing of the paper related to their main expertise). The academic director of the EUGMS assured the coordination of the various chapters and wrote the first draft. All group members participated in its improvement and agreed with the content of the final version. The draft statement was then submitted to the executive boards of the two societies.

Vaccines should be part of a healthy aging strategy, considering that currently the period from retirement age (from 55 to 65 years in most Western European countries) to death is generally two to three decades. Several clinical considerations must be included in it (Table 1):

- Vaccinations: After a complete vaccine history assessment at 60 years of age, recommended vaccines include TdaP, influenza, pneumococcal and herpes zoster. The association of influenza and pneumococcal vaccines has potential preventive effects (1). Choice of TdaP, a tetanus toxoid, reduced diphtheria toxoid and acellular pertussis vaccine follows the recommendation of the US Advisory Committee on Immunization Practices (ACIP) (2). Moreover, this combined vaccine reduces the reservoir of pertussis in the population at large, decreases exposure of persons at increased risk of complicated infections (e.g., infants) and also reduces the cost and disruption of pertussis in health care facilities and other institutional settings (2). These different and/or sequential vaccine shots more often cause local and transitory reactions than systemic ones.

Table 1 - Proposed vaccine guidelines for adults aged 60 years and older in Western Europe.

\begin{tabular}{|c|c|c|}
\hline Vaccine program & Recommended vaccines & Clinical considerations \\
\hline \multirow[t]{4}{*}{$\begin{array}{l}\text { Starting at } 60 \text { years } \\
\text { (but possibly earlier) }\end{array}$} & Tetanus-Diphtheria-Pertussis (TdaP) & $\begin{array}{l}\text { Assess vaccine status } \\
\text { - If no evidence of any previous vaccination, start a new complete } \\
\text { vaccination series. } \\
\text { - If last booster } \geq 10 \text { years before, give a booster dose }\end{array}$ \\
\hline & Trivalent Influenza Vaccine (TIV) & Adapted to annual strain \\
\hline & Pneumococcal (PV23) & Assess vaccine status: if vaccine administered $\geq 5$ years before, give 1 dose \\
\hline & Herpes Zoster & $\begin{array}{l}\text { Assess vaccine status: } \\
\text { If no evidence of any previous vaccination, give } 1 \text { dose }\end{array}$ \\
\hline \multirow[t]{4}{*}{ Revaccinations } & Influenza (TIV) & Every YEAR \\
\hline & Pneumococcal (PV23) & Every FIVE YEARS \\
\hline & Tetanus-Diphtheria-Pertussis (TdaP) & Every TEN YEARS \\
\hline & Herpes Zoster & Not yet determined \\
\hline
\end{tabular}

Special indications

\begin{tabular}{|c|c|c|}
\hline 1. New injury event & $\begin{array}{l}\text { Tetanus-Toxoid (TT) or } \\
\text { Tetanus-Diphtheria toxoids (Td) } \\
\text { or TdaP }\end{array}$ & $\begin{array}{l}\text { - If no evidence of any previous vaccination, start a new complete } \\
\text { vaccination series. } \\
\text { - If last booster } \geq 10 \text { years before, give a new booster dose }\end{array}$ \\
\hline $\begin{array}{l}\text { 2. Repeated hospital } \\
\text { admissions }\end{array}$ & Pneumococcal & Ask vaccine history: if vaccine administered $\geq 5$ years, provide a booster \\
\hline \multirow[t]{6}{*}{$\begin{array}{l}\text { 3. Nursing home } \\
\text { admissions }\end{array}$} & Tetanus-Diphtheria-Pertussis (TdaP) & $\begin{array}{l}\text { If no evidence of any previous vaccination, start a new complete } \\
\text { vaccination series. }\end{array}$ \\
\hline & & - If last booster $\geq 10$ years before, give a new booster dose \\
\hline & \multirow[t]{2}{*}{ Influenza (TIV) } & No upper age limit; \\
\hline & & $\begin{array}{l}\text { Herd immunity is important for both residents of nursing home and } \\
\text { healthcare professionals }\end{array}$ \\
\hline & Pneumococcal & $\begin{array}{l}\text { If already vaccinated, a booster is recommended if initial vaccination } \\
\text { was } \geq 5 \text { years }\end{array}$ \\
\hline & Herpes Zoster & $\begin{array}{l}\text { If not already administered, give } 1 \text { dose. If already vaccinated, need } \\
\text { for revaccination is not yet known }\end{array}$ \\
\hline
\end{tabular}

Contra-indications and precautions for every vaccine: Refer to official vaccine recommendations.

http://www.ecdc.eu.int

http://www.cdc.gov/mmwr/preview/mmwrhtml/rr5510a1.htm

http://www.clinicalanswers.nhs.uk/index.cfm?question $=643$

All the above-mentioned vaccines can be administered in the event of: Mild to moderate local reactions after a previous vaccination, mild acute illness, current antimicrobial therapy, persons receiving anticoagulant therapy, recent exposure to an infectious disease and stable neurological disorder.

Administration: Maintain recommended vaccine storage temperature, and sterile injection technique, as well as injection route and site (e.g., persons on anticoagulant therapy can receive subcutaneous instead of intramuscular injections).

A patient vaccination card is strongly recommended. 
- Revaccinations: an annual influenza vaccination is needed, as each year's vaccine is adapted to new seasonal strains. Repeated annual influenza immunizations broaden antigenic protection, if the new strains are closely related (3). Pneumococcal vaccine is recommended every 5 years and TdaP every 10 years. Further studies are needed to determine the duration of the protective effect of a single herpes zoster vaccination and to establish whether a booster for it is required. Regular booster vaccinations throughout life are important to maintain the ability to respond to recall antigens with aging.

Other special indications for vaccinations should be considered:

- In case of trauma or a new medical event, a booster (or a complete vaccination) of tetanus toxoid or TdaP may be provided if the previous tetanus vaccination was given over 10 years previously.

- In case of repeated hospitalizations, pneumococcal vaccine should be considered, if the last immunization dated back 5 years.

- At the time of admission to residential care (approximately 85 years in most Western European countries), a new clinical assessment of vaccine history is recommended, to ascertain if any vaccine updates are needed. This assessment needs to consider TdaP, influenza, pneumococcal and herpes zoster vaccines.

\section{Willingness to vaccinate and public acceptance of vaccination}

These vaccine guidelines for citizens aged 60 years and older, proposed by the two European geriatric and gerontological societies, would be justified if there is evidence such programs are cost-effective and safe.

Despite existing controversies concerning: a) estimated influenza-related mortality; b) the effectiveness of influenza vaccine in older adults; c) possible selection biases in cohort studies $(4,5)$; and d) the need for country-specific assessment (6). Most recent analysis studies of influenza vaccine show a high-impact, cost-effective service for persons aged over 50 years, and even over 70 years (7-11). Already in the mid-1990s, a cost-effectiveness analysis of pneumococcal vaccination for prevention of invasive pneumococcal disease in populations aged over 65 years in 10 Western European countries justified wider use of the vaccine (12). Most cost-effectiveness analyses of pertussis vaccination in Europe were performed in Germany and based on a Markov model; the results were more sensitive in favoring routine vaccination of adults aged 20 to 64 with TdaP, if the incidence of pertussis in this age group was greater than 120 per 100,000 population $(13,14)$.

More research is needed on the cost-effectiveness of all these vaccines in adults aged 60 years and older. Community and patient values for preventing herpes zoster and post-herpetic neuralgia are currently under investigation to determine the quality-adjusted life-years saved (1517). Improving vaccine uptake in this population requires addressing numerous barriers to adult immunization, which involve both consumers' beliefs and healthcare professionals' practices $(18,19)$.

\section{Consensus statement}

The EUGMS and IAGG-ER have formed a Joint Working Group to complement existing information, propose vaccine guidelines, and develop a consensus statement that advocates immunization in adults aged 60 years and older. This consensus statement:

- Demonstrates the need to strengthen and harmonize vaccine strategies at the European level;

- Recognises the importance of sustaining a life-course vaccine program;

- Promotes healthy aging by increasing vaccine coverage to limit the burden of vaccine-preventable infectious diseases;

- Supports the public health, social and economic value of vaccination, and even

- Improves willingness to vaccinate the most rapidly growing segment of the general population.

Healthcare professionals have a critical role to play in the implementation of such consensus vaccine guidelines. Communication and awareness of vaccine-preventable diseases, such as an efficient reminder, recall and information system as well as improved access to vaccines, constitute the main pillars for success in establishing a vaccine program for European citizens aged 60 years and older.

\section{ACKNOWLEDGEMENT}

European Union Geriatric Medicine Society (EUGMS), representing 32 national geriatric societies of European countries.

International Association of Geriatrics and Gerontology - European Region (IAGG-ER), representing national societies from $43 \mathrm{Eu}-$ ropean countries.

The authors would like to thank Jean-Pierre Baeyens (B), Peter Crome (UK), Luc Hessel (F), Yves Megard (F) and Eva Topinkova ( $\mathrm{Cz}$ ) for their valuable comments on this paper.

\section{REFERENCES}

1. Christenson B, Hedlund J, Lundbergh P, Ortquist A. Additive preventive effect of influenza and pneumococcal vaccines in elderly persons. Eur Respir J 2004; 23: 363-8.

2. Kretsinger K, Broder KR, Cortese MM et al. Preventing tetanus, diphtheria, and pertussis among adults: use of tetanus toxoid, reduced diphtheria toxoid and acellular pertussis vaccine recommendations of the Advisory Committee on Immunization Practices (ACIP) and recommendation of ACIP, supported by the Healthcare Infection Control Practices Advisory Committee (HICPAC), for use of TdaP among health-care personnel. MMWR Recomm Rep 2006; 55: 1-37.

3. Smith NM, Bresee JS, Shay DK, Uyeki TM, Cox NJ, Strikas RA. Prevention and Control of Influenza: recommendations of the Advisory Committee on Immunization Practices (ACIP). MMWR Recomm Rep 2006; 55: 1-42. 
J-P. Michel, C. Chidiac, B. Grubeck-Loebenstein et al.

4. Simonsen L, Reichert TA, Viboud C, Blackwelder WC, Taylor RJ, Miller MA. Impact of influenza vaccination on seasonal mortality in the US elderly population. Arch Intern Med 2005; 165: 265-72.

5. Simonsen L, Taylor RJ, Viboud C, Miller MA, Jackson LA Mortality benefits of influenza vaccination in elderly people: an ongoing controversy. Lancet Infect Dis 2007; 7: 658-66.

6. Nicholson KG. Socioeconomics of influenza and influenza vaccination in Europe. Pharmacoeconomics 1996; 9 (Suppl 3): 75-8.

7. Patel MS, Davis MM. Could a federal program to promote influenza vaccination among elders be cost-effective? Prev Med 2006; 42: 240-6.

8. Nichol KL, Nordin J, Mullooly J. Influence of clinical outcome and outcome period definitions on estimates of absolute clinical and economic benefits of influenza vaccination in community dwelling elderly persons. Vaccine 2006; 24: 1562-8.

9. Maciosek MV, Solberg LI, Coffield AB, Edwards NM, Goodman MJ. Influenza vaccination health impact and cost effectiveness among adults aged 50 to 64 and 65 and older. Am J Prev Med 2006; 31: 72-9

10. Turner DA, Wailoo AJ, Cooper NJ, Sutton AJ, Abrams KR Nicholson KG. The cost-effectiveness of influenza vaccination of healthy adults 50-64 years of age. Vaccine 2006; 24: 1035-43.

11. Prosser LA, O'Brien MA, Molinari NA et al. Non-traditional set- tings for influenza vaccination of adults: costs and cost effectiveness. Pharmacoeconomics 2008; 26: 163-78.

12. Evers SM, Ament AJ, Colombo GL, et al. Cost-effectiveness of pneumococcal vaccination for prevention of invasive pneumococcal disease in the elderly: an update for 10 Western European countries. Eur J Clin Microbiol Infect Dis 2007; 26: 531-40.

13. Lee GM, Murphy TV, Lett $S$ et al. Cost effectiveness of pertussis vaccination in adults. Am J Prev Med 2007; 32: 186-93.

14. Lee GM, Riffelmann M, Wirsing von Konig CH. Cost-effectiveness of adult pertussis vaccination in Germany. Vaccine 2008; 26: 3673-9.

15. Brisson M, Pellissier JM, Levin MJ. Cost-effectiveness of herpes zoster vaccine: flawed assumptions regarding efficacy against postherpetic neuralgia. Clin Infect Dis 2007; 45: 1527-9.

16. Rothberg MB, Virapongse A, Smith KJ. Cost-effectiveness of a vaccine to prevent herpes zoster and postherpetic neuralgia in older adults. Clin Infect Dis 2007; 44: 1280-8.

17. Lieu TA, Ortega-Sanchez I, Ray GT et al. Community and patient values for preventing herpes zoster. Pharmacoeconomics 2008; 26: 235-49.

18. Johnson DR, Nichol KL, Lipczynski K. Barriers to adult immunization. Am J Med 2008; 121: S28-35.

19. Kotchen TA. Why the slow diffusion of treatment guidelines into clinical practice? Arch Intern Med 2007; 167: 2394-5. 